\title{
The Influence of Gravity Loads on the Seismic Design of RBS Connections
}

\author{
R. Montuori* \\ University of Salerno, Via Giovanni Paolo II, Fisciano (SA), Italy
}

\begin{abstract}
Connections with Reduced Beam Section (RBS) have been investigated in the last 20 years both from an analytical point of view and from an experimental point of view. Several experimental tests demonstrated that RBS connections designed according to themost modern seismic codes are able to obtain the desired goal: the protection of the connection due to the yielding of the adjacent RBS. But in all the past researches and experimental tests the role that vertical loads can play was neglected or not properly accounted for. This study proposes a new procedure for accurately computing the relation between RBS location, vertical load and amount of section reduction for ensuring that plastic hinges develop in the reduced sections or in a reduced section and in an intermediate section of the beam.
\end{abstract}

Keywords: Dissipative behaviour, "Dog-Bone" connections, partial strength connections, reduced beam section.

\section{INTRODUCTION}

In the seismic design of moment resisting frames it is universally suggested the use of full-strength connections able to develop sufficient overstrength with respect to the connected beam to allow the complete development of the plastic rotation capacity of the beam. This design goal can be achieved provided that the connection overstrength is properly selected accounting for the strain-hardening occurring before flange local buckling and considering also the influence of random material variability [1].

Such high overstrength significantly affects the connection structural detail requiring strengthening elements such as reinforcing ribs, cover plates, haunches, etc; which significantly affects the cost of connections. For this reason experimental investigations on the cyclic response of partialstrength connections have gained new attention [2-11]. RBS connections can be considered a particular typology within the framework of partial-strength connections, because their flexural resistance is less than the one of the connected beam. RBS connections are also known with the name of "dog-bones" due to the reduction of the beam flange width by means of a "dog-bone" shape at a proper distance from the column flange.

The first idea of RBS was due to A. Plumier in 1980s [12] during a research project financed by the Luxembourg steel producer ARBED and the European Union with the aim of increasing the ductility of the structure by promoting the development of plastic hinges in the beams rather than in the columns. At that time the idea was patented by ARBED.

In 1994 Northridge earthquake and in 1995 Kobe earthquake a lot of unexpected damages to steel moment-resisting frames were observed. These damages were mainly due to the failure of welded beam-to-column connections. For these

*Address correspondence to this author at the University of Salerno, Via Giovanni Paolo II, Fisciano (SA), Italy; Tel: +39 098 963421; Fax: +39 089968764; E-mail: r.montuori@unisa.it reasons ARBED waived any licensing fees and claims and RBS connections started to be investigated by a lot of researchers [13-29].

Since that time one of the main objective of the research concerning the "dog-bone" connections has been the development of design rules able to promote the beam yielding for safeguarding the beam-to-column connections [13-33].

In the following research activity, "dog-bone" connections have been used also for promoting the development of a collapse mechanism of global type. In fact, according to the traditional seismic design philosophy, structures have to remain in elastic range during seismic events having a return period comparable with the service life of the structure. On the contrary, in the case of destructive earthquakes, i.e. events with a return period of 475 years and as a consequence having low probability of occurrence, it is accepted the damage of both structural and nonstructural elements due to the development of dissipative mechanisms. Therefore, the plastic reserves of the structure have to be exploited, only in the case of rare major earthquakes, to dissipate the earthquake input energy in some zones (dissipative zones) of the structure which have to be properly selected.

The column yielding has to be absolutely avoided, because, due to the action of axial forces and the premature occurrence of local buckling, they have a low available ductility. In addition, the failure modes which can result from column hinging could involve a limited number of dissipative zones. For these reasons, aiming at the complete development of the plastic reserves of the structure, modern seismic codes provide simple design criteria whose goal is the prevention of local failure modes and, instead, the promotion of a global mechanism, i.e. a collapse mechanism characterised by the hinging of all the beam ends and the hinging of the base sections of the first storey columns. So, it can be concluded that structures in high seismicity zones are normally designed to resist severe earthquakes by dissipating the input energy by means of inelastic deformations and, in order to maximize this effect, plastic hinges need to be developed at beam ends rather than in the columns in case of 
moment resisting frames (MRFs) [34-43]. However also in the case of other structural typologies the need to avoid the yielding of columns is always the desired goal and the development of a global mechanism is the main design objective [44-57].

In this paper the role played by the vertical load, the amount of the resistance reduction of the weakened section and the distance of RBS from the beam-to-column connection is clearly investigated. In particular, with the aim of obtaining the yielding of both "dog-bones", i.e. the safeguards of beam-to-column connections, the relations occurring among the three quantities above recalled are investigated, pointing out that during the experimental tests on the classical cantilever scheme (where just one "dog-bone" and just one beam-to-column connection are present, Fig. (1)) the obtained results can be affected by an error which could be avoided only by replacing the cantilever scheme with a structural scheme where the whole beam with both dog-bones, both beam-to-column connections and vertical loads are present. In the case of moment resisting frames, the design criterion suggested by seismic codes is the adoption of columns having a flexural resistance greater than that of the connected beams.

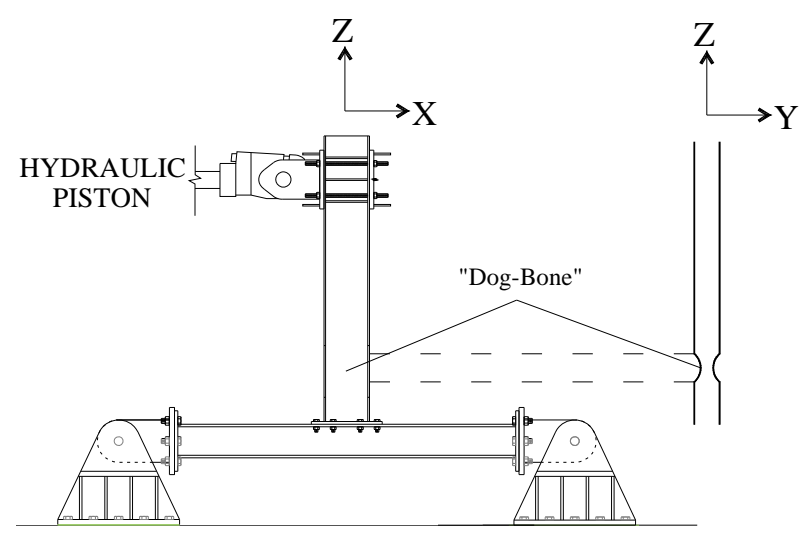

Fig. (1). Typical cantilever scheme for "dog-bone" experimental tests.

Even if the fulfilment of this design criterion, the socalled member hierarchy criterion, is generally able to prevent the development of storey mechanisms, but not sufficient to guarantee the formation of a collapse mechanism of global type, the respect of this hierarchy criterion often causes column oversize leading to design an uneconomical structure.

The use of RBS connections can help to realize a more economical structure. In fact, the maximum moment transmitted by the beam to the column is reduced due to the yielding of "dog-bone", and, as a consequence, the maximum moment transmitted to the column is lower than the beam plastic moment.

Finally, we can summarize the advantages which could come from the use of "dog-bone" connections:

a) the collapse of beam-to-column connections can be prevented assuring the yielding of the beam in a pre-defined location which acts as a fuse; b) the weakened beam section is characterized by the decrease, with respect to the original section, of the widthto-thickness ratio of the flanges, i.e. a reduced local slenderness, which leads to the improvement of the plastic rotation capacity;

c) for given beam sections, the use of "dog-bones" allows the development of a dissipative mechanism by means of columns having a section smaller than that required in the case of unweakened beams.

The above advantages are accompanied by design difficulties regarding both the definition of the "dog-bone" location, with respect to the beam-to-column connection, to prevent connection yielding and the definition of the magnitude of the weakening to be conferred to the beam section. The developed research is aimed to overcome such design difficulties. The goal of the work herein presented is the setting up of design rules regarding the magnitude of the weakening to be realised and the location of the weakened beam sections. In particular, the location of the weakened section has to be selected in order to assure the development of the plastic hinges in "dog-bones" and/or in intermediate beam sections, while the yielding of the beam-to-column connections has to be prevented.

\section{LOCATION OF FIRST PLASTIC HINGE}

One of the most important problem to be solved in seismic design of MRFs is the location of plastic hinges in the beams. Regarding this issue, considering that seismic action can be represented by means of an appropriate distribution of increasing horizontal forces, it is preliminarily necessary to observe which is the shape of the bending moment diagram of a generic beam subjected to both horizontal forces and vertical loads (Fig. (2)).

We can apply the superposition principle by considering separately the effect of vertical loads and the effect of horizontal forces (Fig. (2)). Therefore, the resulting bending moment diagram is given in Fig. (3), where the sections corresponding to the beam ends (sections 1 and 5), those corresponding to the "dog-bone" locations (section 2 and 4) and that corresponding to the maximum bending moment (section 3) have been pointed out.

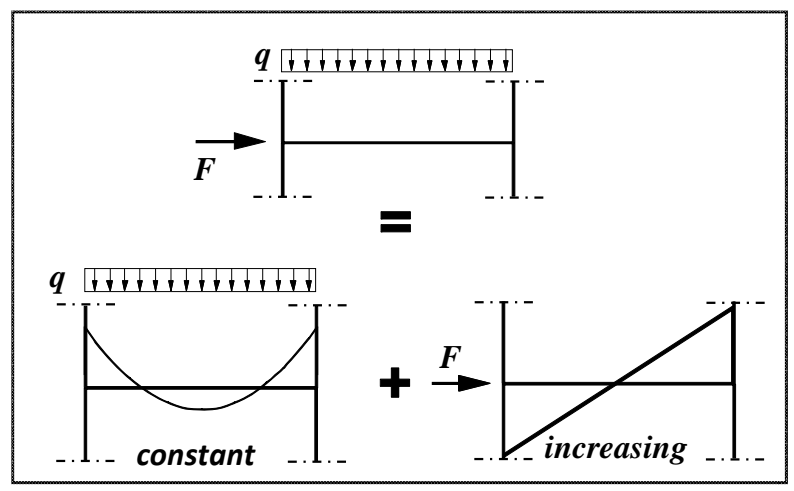

Fig. (2). Bending moment due to vertical loads and seismic forces.

It is evident that the design parameters are the location of the "dog-bones" (which is denoted with the distance $a$ in Fig. (3), and the magnitude of the weakening characterising 
the "dog-bones". This second parameter can be expressed in non-dimensional form as:

$m_{d b}=\frac{M_{p . d b}}{M_{p}}$

where $M_{p . d b}$ is the plastic moment of the weakened beam section and $M_{p}$ is the plastic moment of the complete beam section.

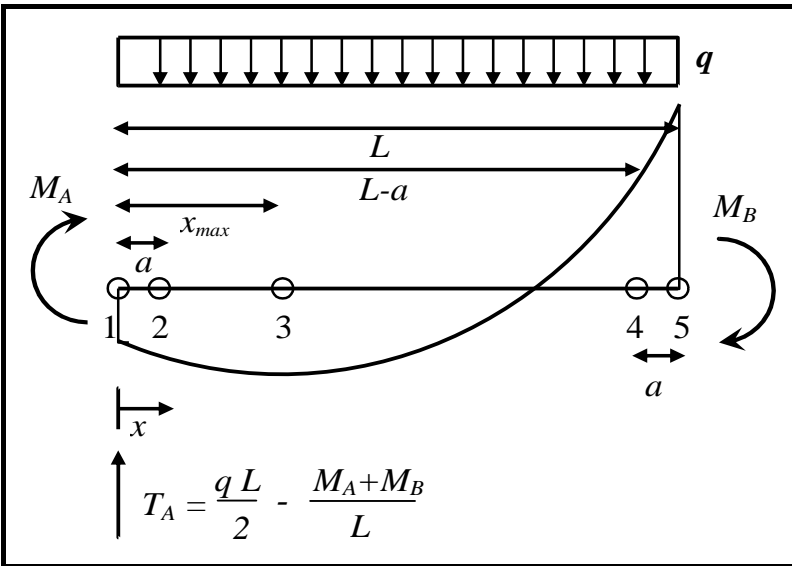

Fig. (3). Total beam bending moment diagram.

In this phase of the design procedure the $m_{d b}$ value can assumed as fixed, while the location $a$ of the "dog-bones" is to be properly selected.

It is important to note that at the left side of the beam (beam sections 1 and 2) the bending moments due to vertical loads and horizontal forces have an opposite sign (one is anticlock-wise and another is clock-wise), while at the right side (beam sections 3 and 4 ) they have the same sign (clockwise).

Due to this consideration it is obvious that for increasing values of horizontal forces the first plastic hinge develops in beam section 4 or 5 rather than in beam section 1 or 2 .

So the first problem to be solved is to find the conditions assuring that sections $1,2,3$ and 5 remain in elastic range, while section 4 yields when seismic horizontal forces increase.

To this aim it is useful to consider the expression of bending moment at the generic section $x$ :

$$
\begin{aligned}
& M(x)=M_{A}+T_{A} x-q \frac{x^{2}}{2}= \\
& =M_{A}+\left(q \frac{L}{2}-\frac{M_{A}+M_{B}}{L}\right) x-q \frac{x^{2}}{2}
\end{aligned}
$$

And the value of $x_{\max }$ representing the abscissa where the bending moment has its maximum value:

$x_{\max }=\frac{L}{2}-\frac{M_{A}+M_{B}}{q L}$

Using Eq. (2) and (3) the bending moment in sections $1,2,3,4$ and 5 can be expressed as:
Section $1 M(0)=M_{A}$

Section 2

$M(a)=q \frac{a(L-a)}{2}-M_{B} \frac{a}{L}+\left(1-\frac{a}{L}\right) M_{A}$

Section 3

$M\left(x_{\max }\right)=\frac{q L^{2}}{8}+\frac{M_{A}-M_{B}}{2}+\frac{\left(M_{A}+M_{B}\right)^{2}}{2 q L^{2}}$

Section 4

$M(L-a)=q \frac{a(L-a)}{2}+M_{A} \frac{a}{L}-\left(1-\frac{a}{L}\right) M_{B}$

Section $5 M(L)=-M_{B}$

The conditions to be fulfilled in order to assure that sections $1,2,3$ and 5 remain in elastic range, while section 4 yields when seismic horizontal forces increase are given by the following relationships:

Section $1 M_{A}<M_{p}$

Section $2 M(a)<m_{d b} M_{p}$

Section $3 M\left(x_{\max }\right)<M_{p}$

Section $4 M(L-a)=-m_{d b} M_{p}$

Section $5 M(L)>-M_{p} \Rightarrow-M_{B}>-M_{p} \Rightarrow M_{B}<M_{p}$

It is easy to recognize that by combining the yielding condition of "dog-bone" of the right side (Eq. (12), section 4) with the value of bending moment at the abscissa $x=L-a$ given by Eq.(7), an expression of $M_{B}$ as a function of $M_{A}$ can be obtained:

$M(L-a)=-m_{d b} M_{p}$

This expression represents the relation occurring between the end moments when the first plastic hinge develops at section 4 corresponding to the right "dog-bone".

By means of Eqs. (14) and (2), it is possible to express the design requirements (9), (10), (11) e (13) as follows:

$M_{A}<M_{A 1}$ with $M_{A l}=M_{p}$

$M_{A}<M_{A 2}=\frac{m_{d b} L}{L-2 a} M_{p}-q \frac{a(L-a)}{2}$

$M_{A}<M_{A 3}$ with

$M_{A 3}=\sqrt{2 q(L-a)^{2}\left(1+m_{d b}\right) M_{p}}+$

$-\left(\frac{q(L-a)^{2}}{2}+m_{d b} M_{p}\right)$

$M_{A}<M_{A 5}$ with

$M_{A 5}=\frac{\left(1-m_{d b}\right) L-a}{a} M_{p}-q \frac{L(L-a)}{2}$ 
Obviously, the first plastic hinge develops in the right "dog-bone" provided that Eq. (13) is satisfied. Under this condition, it is required that the second plastic hinge develops either in the left "dog-bone" or an intermediate beam section. On the contrary, the yielding of the beam ends close to the beam-to-column connections has to be prevented, because, as already stated, the use of "dog-bones" is also aimed at the protection of beam-to-column connections.

It is easy to recognise that increasing the seismic horizontal forces, i.e. increasing $M_{A}$, relationships (15), (16), (17) and (18) allow to identify the section where the second plastic hinge develops. To this scope, it is sufficient to control what is the minimum limit value among $M_{A 1}, M_{A 2}, M_{A 3}, M_{A 5}$. In other words, it is sufficient to identify the first relationship to be unsatisfied as far as $M_{A}$ increases.

Therefore, all the yielding conditions can be expressed by means of the limit values $M_{A i}$ (with $\mathrm{i}=1,2,3,5$ ) of the bending moment $M_{A}$ occurring at the first beam end. In particular, the condition:

$M_{A 3}<M_{A 2}$ condition A

identifies the $a$ values assuring that the yielding of the beam in the section where the maximum sagging moment occurs (section 3) precedes the yielding of the left "dogbone" (section 2); the condition:

$M_{A 3}<M_{A 5}$ condition B

identifies the $a$ values assuring that the beam yielding (section 3) precedes the yielding of the connection B (section 5); the condition:

$M_{A 2}<M_{A 5}$ condition C

identifies the $a$ values assuring that the left "dog-bone" yielding (section 2) precedes the yielding of the connection $\mathrm{B}$ (section 5); the condition:

$M_{A 3}<M_{A 5}$ condition D

identifies the $a$ values assuring that the beam yielding (section 3) precedes the yielding of the left connection A (section 1); finally, the condition:

$M_{A 2}<M_{A 1}$ condition E

identifies the $a$ values assuring that the yielding of the left "dog-bone" (section 2) precedes the yielding of the left connection A (section 1).

It is evident that conditions (20), (21), (22), (23) have to be absolutely satisfied, because they assure the development of the second plastic hinge either in the left "dog-bone" or in the intermediate beam section where the maximum sagging moment occurs, while the yielding of the connections at the beam ends is prevented. In other words, relationships (20), (21), (22) and (23) are the design requirements.

Conversely, condition (19), depending on its fulfilment or not, can be used to discern if the second plastic hinge develops in the left "dog-bone" or in the intermediate beam section.

Such conditions give rise to the following nondimensional relationships:

\section{Condition A:}

$$
\begin{aligned}
& 4\left(\frac{a}{L}\right)^{3}+\left(4 \sqrt{2\left(1+m_{d b}\right) \frac{M_{p}}{q L^{2}}}-8\right)\left(\frac{a}{L}\right)^{2} \\
& +\left(5+4 m_{d b} \frac{M_{p}}{q L^{2}}-6 \sqrt{2\left(1+m_{d b}\right) \frac{M_{p}}{q L^{2}}}\right)\left(\frac{a}{L}\right) \\
& -4 m_{d b} \frac{M_{p}}{q L^{2}}-1+2 \sqrt{2\left(1+m_{d b}\right) \frac{M_{p}}{q L^{2}}}<0
\end{aligned}
$$

whose solutions are:

$\frac{a}{L}<\frac{a_{3}}{L} \quad$ and $\quad \frac{a_{2}}{L}<\frac{a}{L}<\frac{a_{1}}{L}$

where:

$\frac{a_{1}}{L}=1$

$\frac{a_{2}}{L}=\frac{1}{2}-\sqrt{\frac{\left(1+m_{d b}\right)}{2} \frac{M_{p}}{q L^{2}}}+\sqrt{\frac{\left(1-m_{d b}\right)}{2} \frac{M_{p}}{q L^{2}}}$

$\frac{a_{3}}{L}=\frac{1}{2}-\sqrt{\frac{\left(1+m_{d b}\right)}{2} \frac{M_{p}}{q L^{2}}}-\sqrt{\frac{\left(1-m_{d b}\right)}{2} \frac{M_{p}}{q L^{2}}}$

Condition B:

$$
\begin{aligned}
& -\left(\frac{a}{L}\right)^{3}+\left(1-2 \sqrt{2\left(1+m_{d b}\right) \frac{M_{p}}{q L^{2}}}\right)\left(\frac{a}{L}\right)^{2} \\
& +\left(2\left(1-m_{d b}\right) \frac{M_{p}}{q L^{2}}+2 \sqrt{2\left(1+m_{d b}\right) \frac{M_{p}}{q L^{2}}}\right)\left(\frac{a}{L}\right) \\
& -2\left(1-m_{d b}\right) \frac{M_{p}}{q L^{2}}<0
\end{aligned}
$$

whose solution are:

$\frac{a_{6}}{L}<\frac{a}{L}<\frac{a_{5}}{L} \quad$ and $\quad \frac{a}{L}>\frac{a_{4}}{L}$

where:

$\frac{a_{4}}{L}=1$

$\frac{a_{5}}{L}=-\sqrt{2\left(1+m_{d b}\right) \frac{M_{p}}{q L^{2}}}+2 \sqrt{\frac{M_{p}}{q L^{2}}}$

$\frac{a_{6}}{L}=-\sqrt{2\left(1+m_{d b}\right) \frac{M_{p}}{q L^{2}}}-2 \sqrt{\frac{M_{p}}{q L^{2}}}$

\section{Condition C:}

$$
\begin{aligned}
& -2\left(\frac{a}{L}\right)^{4}+5\left(\frac{a}{L}\right)^{3}-4\left(1+\frac{M_{p}}{q L^{2}}\right)\left(\frac{a}{L}\right)^{2} \\
& +\left(1+2\left(3-m_{d b}\right) \frac{M_{p}}{q L^{2}}\right) \frac{a}{l}-2\left(1-m_{d b}\right) \frac{M_{p}}{q L^{2}}<0
\end{aligned}
$$


whose solutions are:

$\frac{a}{L}<\frac{a_{8}}{L} \quad$ and $\quad \frac{a}{L}>\frac{a_{7}}{L}$

where:

$\frac{a_{7}}{l}=1$

$\frac{a_{8}}{l}=\frac{1}{2}+\frac{1}{6} \sqrt[3]{T}-6 \frac{\frac{2}{3} \frac{M_{p}}{q l^{2}}-\frac{1}{12}}{\sqrt[3]{T}}$

with:

$T=-108 m_{d b} \frac{M_{p}}{q L^{2}}+$

$+3\left[-3+72 \frac{M_{p}}{q L^{2}}-576\left(\frac{M_{p}}{q L^{2}}\right)^{2}+\right.$

$\left.+1296 m_{d b}^{2}\left(\frac{M_{p}}{q L^{2}}\right)^{2}+1536\left(\frac{M_{p}}{q L^{2}}\right)^{3}\right]^{1 / 2}$

\section{Condition D:}

Condition D can be written as follows (by expressing relationship (22) by means of $M_{A 1}$ and $M_{A 3}$ values given by Eqs. (15) and (17), respectively):

$-\left[\frac{a}{L}+\left(1-\sqrt{2(1+m) \frac{M_{p}}{q L^{2}}}\right)\right]^{2}<0$

therefore, condition $D$ is always satisfied.

\section{Condition E:}

By means of Eq.(15) and (16) this condition provides:

$2\left(\frac{a}{L}\right)^{3}-3\left(\frac{a}{L}\right)^{2}-\left(4 \frac{M_{p}}{q L^{2}}-1\right)\left(\frac{a}{L}\right)+$

$+2(1-m) \frac{M_{P}}{q L^{2}}>0$

In order to show that this condition is always verified when the condition $\mathrm{C}$ is verified, it is useful to write the condition $\mathrm{C}$ (Eq.(31)) in the following way:

$$
\begin{aligned}
& \left(\frac{a}{L}-1\right)\left[-2\left(\frac{a}{L}\right)^{3}+3\left(\frac{a}{L}\right)^{2}-\left(1+4 \frac{M_{p}}{q L^{2}}\right)\left(\frac{a}{L}\right)+\right. \\
& \left.+2(1-m) \frac{M_{p}}{q L^{2}}\right]<0
\end{aligned}
$$

Being $a / L<1$ this relation is equivalent to require:

$$
\begin{aligned}
& {\left[-2\left(\frac{a}{L}\right)^{3}+3\left(\frac{a}{L}\right)^{2}-\left(1+4 \frac{M_{p}}{q L^{2}}\right)\left(\frac{a}{L}\right)+\right.} \\
& \left.+2(1-m) \frac{M_{p}}{q L^{2}}\right]>0
\end{aligned}
$$

Now it is easy to verify that the first member of Eq. (35) is greater than the first member of Eq.(37) when the following relation is satisfied:
$-4\left(\frac{a}{L}\right)^{3}+6\left(\frac{a}{L}\right)^{2}-2\left(\frac{a}{L}\right)<0$

The solutions of Eq. (38) are:

$\frac{a}{L}>1 \quad$ and $\quad 0<\frac{a}{L}<\frac{1}{2}$

Now it can be observed that, being $a / L<1 / 2$ (which means that a "dog-bone" cannot be located beyond the midspan), Eq. (38) is always true, and so condition $E$ is always satisfied if condition $C$ is satisfied.

Therefore, in the range $0<a / L<1 / 2$, which is the significant one from the design point of view, only the three conditions $A, B$ and $C$ remain to be analysed. These three remaining condition provide the following significant solutions (32):

Condition A $\frac{a}{L}<\frac{a_{3}}{L} \quad$ and $\quad \frac{a}{L}>\frac{a_{2}}{L}$

which is obtained from Eqs. (25) and (26);

Condition B $\frac{a}{L}<\frac{a_{5}}{L}$

which is obtained from Eqs. (28) and (29) by observing that $a_{6}$ provides negative values which are not significant;

Condition C $\frac{a}{L}<\frac{a_{8}}{L}$

which is obtained from Eqs. (31) and (32). Therefore, taking into account that condition $A$ has to be used only to recognise the location of the second plastic hinge which can develop either at the left "dog-bone" or at an intermediate beam section, it means that conditions $B$ and $C$ show the existence of an upper bound concerning the parameter $a$ expressing the "dog-bone" location (this upper bound value is given by the minimum value between $a_{5}$ and $a_{8}$ ).

Therefore, the design solution concerning the "dog-bone" location can be expressed as follows: the smallest value between $a_{5}$ and $a_{8}$ is the upper bound of $a$, while the location of the second plastic hinge depends on $a_{2}$ and $a_{3}$ value; in particular, according to Eq. (40), if $a<a_{3}$ or $a>a_{2}$ the second plastic hinge develops in the intermediate beam section, where the maximum sagging moment occurs, otherwise the second plastic hinge occurs at the left "dog-bone".

In addition, when relation (40) is satisfied, the location $x_{\max }$ of the second plastic hinge where the maximum sagging moment occurs can be determined by solving the following equation:

$T(x)=T_{A}-q x=\frac{q L}{2}-\frac{M_{A}+M_{B}}{L}-q x=0$

which provides:

$x_{\max }=\frac{L}{2}-\frac{M_{A}+M_{B}}{q L}=$

$=\frac{L-a}{2}-\frac{M_{A}}{q(L-a)}-\frac{m_{d b} M_{p}}{q(L-a)}$

The value of $M_{A}$ to be used in relationship (43) is equal to $M_{A 3}$ consistently with condition A expressed by Eq. (19). 
By substituting the $M_{A 3}$ value in Eq. (44) $x_{\max }$ becomes:

$$
x_{\max }=L-a-\left(\frac{2 M_{p}\left(1+m_{d b}\right)}{q}\right)^{1 / 2}
$$

\section{LOCATION OF THE SECOND PLASTIC HINGE:}

As the expression for computing $a_{8} / L$ is particularly complex, in order to identify the governing limit value of $a / L$, a numerical analysis has been carried out. For any given value of $m_{d b}$, by varying the non-dimensional parameter $M_{p} / q L^{2}$ in the range between $1 / 16$ and zero, which covers all the possible design situations, the values of $a_{2}, a_{3}, a_{5}$ and $a_{8}$ have been computed.

The results of this numerical analysis is presented in Tables 1-6 for $m_{d b}$ equal to $0.4,0.5,0.6,0.7,0.8$, and 0.9 respectively. In addition, the curves representing the values of $a_{2}, a_{3}, a_{5}$ and $a_{8}$ are plotted in Figs. (4-9).

From the analysis of the above recalled figures it is evident the existence of two limit values of $q L^{2} / M_{p}$ which are $q_{\text {lim } I} L^{2} / M_{p}$ and $q_{\lim 2} L^{2} / M_{p}$.

The first one represents the value for which $a_{2}, a_{5}$ and $a_{8}$ are coincident while the second one represents the value for which $a_{3}, a_{5}$ and $a_{8}$ are coincident. These values have been highlighted in bold type in Tables 1-6. Such limit values can be easily determined by means of relationships (26) and (29) providing $a_{2}, a_{3}$, and $a_{5}$. In fact, $q_{\text {lim } 1}$ can be obtained by equating $a_{2}$ and $a_{5}$, while $q_{\text {lim2 }}$ can be obtained by equating $a_{3}$ and $a_{5}$.

The following relationships are thus obtained:

$$
\begin{aligned}
q_{\lim 1}= & \frac{4 M_{p}}{L^{2}}\left(5-\sqrt{8\left(1-m_{d b}\right)}-2 \sqrt{2\left(1+m_{d b}\right)}\right. \\
& \left.+\sqrt{1-m_{d b}^{2}}\right) \\
q_{\lim 2}= & \frac{4 M_{p}}{L^{2}}\left(5+\sqrt{8\left(1-m_{d b}\right)}-2 \sqrt{2\left(1+m_{d b}\right)}\right. \\
& \left.-\sqrt{1-m_{d b}^{2}}\right)
\end{aligned}
$$

As a conclusion, the design solution concerning the "dogbone" location and its influence on the location of the second plastic hinge can be expressed as follows:

case $\mathbf{q}<\mathbf{q}_{\lim 1}$ : the design requirement is $a<a_{8}$, while, regarding the development of the second plastic hinge, if $a<$ $a_{2}$ the yielding of the second "dog-bone" occurs, otherwise the yielding of the beam develops;

case $\mathbf{q}_{\text {lim } 1}<\mathbf{q}<\mathbf{q}_{\text {lim2 }}$ : the design requirement is $a<a_{5}$, while, regarding the development of the second plastic hinge, if $a>a_{3}$ the yielding of the second "dog-bone" occurs, otherwise the yielding of the beam develops;

case $\mathbf{q}>\mathbf{q}_{\text {lim2 }}$ : the design requirement is $a<a_{8}$, while, regarding the development of the second plastic hinge, it always develops at the intermediate beam section where the maximum sagging moment occurs.

The result above reported clarifies the role played by the vertical load $q$ concerning the "dog-bone" location. In par- ticular, it can be noted that, for a given value of the "dogbone" non dimensional resistance $m_{d b}$, the increase of the vertical load $q$ causes a decrease of the maximum allowed value of $a / L$.

Similarly, for a given value of the vertical load $q$, the increase of $m_{d b}$ leads to the decrease of the admissible range for $a / L$.

In addition, by means of the described figures, it is possible to understand what happens when the $a / L$ upper limit for the location of the "dog-bones" is not respected. In fact, it is sufficient to observe which are the conditions providing the limit value of $a_{8} / L$ and $a_{5} / L$.

When $q_{\lim 1}<q<q_{\lim 2}$, then the design limit of $a / L$ is given by $a_{5} / L$, i.e. condition $\boldsymbol{B}$ (Eq. (41)) which identifies the $a$ values assuring that the beam yielding (section 3 ) precedes the yielding of the right connection (section 5).

It means that, if $a / L$ is greater than $a_{5} / L$ the second plastic hinge occurs in the beam-to-column connection located at section 5 .

When $q<q_{\text {lim } 1}$ or $q>q_{\text {lim2 } 2}$ the governing condition is the one corresponding to $a_{8} / L$ limit, i.e. condition $C$ which identifies the $a$ values assuring that the left "dog-bone" yielding (section 2) precedes the yielding of connection $\boldsymbol{B}$ (section 5). It means that, if $a / L$ is greater than $a_{8} / L$, the second plastic hinge occurs in the beam-to-column connection located at the $\boldsymbol{B}$ end.

The above observations show that experimental tests on the classical cantilever scheme, as depicted in Fig. (1), cannot be completely exhaustive, because the information coming from these tests are not able to assure that the second plastic hinge develops in the beam section, where the maximum bending moment occurs, or in the second dog-bone rather than in the beam-to-column connection located at the $\boldsymbol{B}$ end close to the tested "dog-bone".

Its is interesting to note that the $q_{\text {lim }}$ value already found in [34] for full-strength beam-to-column joints can be obtained as a particular case from Eqs. (46) and (47). In fact, for $m_{d b}=1$, i.e. in absence of "dog-bones", the above equations provide:

$q_{\lim 1}=q_{\lim 2}=q_{\lim }=\frac{4 M_{p}}{L^{2}}$

Comparing Figs. (3-9) it is evident that the range where "dog bones" can be located, assuring the protection of the beam-to-column connections, decreases as $m_{d b}$ increases. In particular, for high values of $m_{d b}$ the width of such range is so limited that it could be incompatible with the length of the weakened beam zone required for an appropriate spreading of plasticity.

\section{DESIGN ABACUS FOR "DOG-BONE" LOCATION}

The solution obtained in the previous section, needs the evaluation of $q_{\lim 1}, q_{\text {lim } 2}, a_{5} / L, a_{8} / L$ and at least one between $a_{2} / L$ and $a_{3} / L$.

From a practical point of view, it could appear too complex. In order to simplify the solution of the problem, it is of fundamental importance to highlight that the design goal 
Table 1. Values of $a_{2}, a_{3}, a_{5}$ and $a_{8}$ for $m_{d b}=0.4$.

\begin{tabular}{|c|c|c|c|c|}
\hline$q \mathbf{L}^{2} / \mathbf{M}_{p}$ & $\mathbf{a}_{2} / \mathbf{L}$ & $\mathbf{a}_{3} / \mathbf{L}$ & $a_{5} / \mathbf{L}$ & $\mathbf{a}_{8} / \mathbf{L}$ \\
\hline 0.01 & -2.3894 & -13.3438 & 3.2668 & 0.2998 \\
\hline 0.50 & 0.0914 & -1.4578 & 0.4620 & 0.2892 \\
\hline 1.00 & 0.2111 & -0.8844 & 0.3267 & 0.2777 \\
\hline 1.52 & 0.2653 & -0.6244 & 0.2653 & 0.2653 \\
\hline 4.00 & 0.3555 & -0.1922 & 0.1633 & 0.2039 \\
\hline 5.00 & 0.3708 & -0.1191 & 0.1461 & 0.1817 \\
\hline 6.00 & 0.3820 & -0.0652 & 0.1334 & 0.1623 \\
\hline 7.00 & 0.3908 & -0.0232 & 0.1235 & 0.1457 \\
\hline 11.00 & 0.4129 & 0.0826 & 0.0985 & 0.1009 \\
\hline 11.71 & 0.4156 & 0.0955 & 0.0955 & 0.0955 \\
\hline 12.00 & 0.4166 & 0.1004 & 0.0943 & 0.0934 \\
\hline 13.00 & 0.4199 & 0.1161 & 0.0906 & 0.0869 \\
\hline 14.00 & 0.4228 & 0.1300 & 0.0873 & 0.0812 \\
\hline 15.00 & 0.4254 & 0.1426 & 0.0843 & 0.0762 \\
\hline 16.00 & 0.4278 & 0.1539 & 0.0817 & 0.0718 \\
\hline
\end{tabular}

Table 2. Values of $a_{2}, a_{3}, a_{5}$ and $a_{8}$ for $m_{d b}=0.5$.

\begin{tabular}{|c|c|c|c|c|}
\hline$q \mathbf{L}^{2} / \mathbf{M}_{\mathbf{p}}$ & $\mathbf{a}_{2} / \mathbf{L}$ & $\mathbf{a}_{3} / \mathbf{L}$ & $\mathbf{a}_{5} / \mathbf{L}$ & $\mathbf{a}_{8} / \mathbf{L}$ \\
\hline 0.01 & -3.1603 & -13.1603 & 2.6795 & 0.2498 \\
\hline 0.50 & 0.1340 & -1.4319 & 0.2679 & 0.2260 \\
\hline 1.00 & 0.2412 & -0.8660 & 0.1895 & 0.2020 \\
\hline 1.61 & 0.2113 & -0.5774 & 0.2113 & 0.2113 \\
\hline 4.00 & 0.3363 & -0.1830 & 0.1198 & 0.1412 \\
\hline 5.00 & 0.3506 & -0.1109 & 0.1094 & 0.1263 \\
\hline 6.00 & 0.3617 & -0.0577 & 0.1013 & 0.1137 \\
\hline 7.00 & 0.3706 & -0.0163 & 0.0947 & 0.5000 \\
\hline 10.68 & 0.3880 & 0.0820 & 0.0820 & 0.0820 \\
\hline 11.00 & 0.3943 & 0.0881 & 0.0774 & 0.0743 \\
\hline 12.00 & 0.3985 & 0.1057 & 0.0743 & 0.0693 \\
\hline 13.00 & 0.4022 & 0.1211 & 0.0716 & 0.0650 \\
\hline 14.00 & 0.4055 & 0.1349 & 0.0692 & 0.0611 \\
\hline 15.00 & 0.4085 & 0.1473 & 0.0670 & 0.0577 \\
\hline 16.00 & 0.3525 & 0.1585 & 0.1080 & 0.1242 \\
\hline
\end{tabular}


Table 3. Values of $a_{2}, a_{3}, a_{5}$ and $a_{8}$ for $m_{d b}=0.6$.

\begin{tabular}{|c|c|c|c|c|}
\hline$q \mathbf{L}^{2} / \mathbf{M}_{p}$ & $\mathbf{a}_{2} / \mathbf{L}$ & $\mathbf{a}_{3} / \mathbf{L}$ & $a_{5} / \mathbf{L}$ & $\mathbf{a}_{8} / \mathbf{L}$ \\
\hline 0.01 & -3.9721 & -12.9164 & 2.1115 & 0.1998 \\
\hline 0.50 & -0.1325 & -1.3974 & 0.2986 & 0.1881 \\
\hline 1.00 & 0.0528 & -0.8416 & 0.2111 & 0.1765 \\
\hline 1.73 & 0.1604 & -0.5189 & 0.1604 & 0.1604 \\
\hline 4.00 & 0.2764 & -0.1708 & 0.1056 & 0.1198 \\
\hline 5.00 & 0.3000 & -0.1000 & 0.0944 & 0.1064 \\
\hline 6.00 & 0.3174 & -0.0477 & 0.0862 & 0.0953 \\
\hline 7.00 & 0.3310 & -0.0071 & 0.0798 & 0.0861 \\
\hline 10.00 & 0.3586 & 0.0758 & 0.0668 & 0.0661 \\
\hline 11.00 & 0.3652 & 0.0955 & 0.0637 & 0.0612 \\
\hline 12.00 & 0.3709 & 0.1127 & 0.0609 & 0.0570 \\
\hline 13.00 & 0.3760 & 0.1279 & 0.0586 & 0.0534 \\
\hline 14.0 & 0.3805 & 0.1414 & 0.0564 & 0.0501 \\
\hline 15.0 & 0.3845 & 0.1536 & 0.0545 & 0.0472 \\
\hline 16.0 & 0.3882 & 0.1646 & 0.0528 & 0.0446 \\
\hline
\end{tabular}

Table 4. Values of $a_{2}, a_{3}, a_{5}$ and $a_{8}$ for $m_{d b}=0.7$

\begin{tabular}{|c|c|c|c|c|}
\hline$q L^{2} / M_{p}$ & $\mathbf{a}_{2} / \mathbf{L}$ & $\mathbf{a}_{3} / \mathbf{L}$ & $a_{5} / L$ & $\mathbf{a}_{8} / \mathbf{L}$ \\
\hline 0.01 & -4.8466 & -12.5925 & 1.5609 & 0.1498 \\
\hline 0.50 & -0.2561 & -1.3516 & 0.2207 & 0.1392 \\
\hline 1.00 & -0.0347 & -0.8093 & 0.1561 & 0.1291 \\
\hline 1.91 & 0.1130 & -0.4477 & 0.1130 & 0.1130 \\
\hline 4.00 & 0.2327 & -0.1546 & 0.0780 & 0.0853 \\
\hline 5.00 & 0.2609 & -0.0855 & 0.0698 & 0.0757 \\
\hline 6.00 & 0.2817 & -0.0345 & 0.0637 & 0.0679 \\
\hline 7.00 & 0.2979 & 0.0051 & 0.0590 & 0.0615 \\
\hline 10.00 & 0.3309 & 0.0860 & 0.0494 & 0.0475 \\
\hline 11.00 & 0.3388 & 0.1053 & 0.0471 & 0.0442 \\
\hline 12.00 & 0.3457 & 0.1221 & 0.0451 & 0.0412 \\
\hline 13.00 & 0.3517 & 0.1369 & 0.0433 & 0.0386 \\
\hline 14.00 & 0.3571 & 0.1501 & 0.0417 & 0.0363 \\
\hline 15.00 & 0.3620 & 0.1620 & 0.0403 & 0.0343 \\
\hline 16.00 & 0.3663 & 0.1727 & 0.0390 & 0.0325 \\
\hline
\end{tabular}


Table 5. Values of $a_{2}, a_{3}, a_{5}$ and $a_{8}$ for $m_{d b}=0.8$.

\begin{tabular}{|c|c|c|c|c|}
\hline$q L^{2} / M_{p}$ & $\mathbf{a}_{2} / \mathbf{L}$ & $\mathbf{a}_{3} / \mathbf{L}$ & $\mathbf{a}_{5} / \mathbf{L}$ & $\mathbf{a}_{8} / \mathbf{L}$ \\
\hline 0.01 & -5.8246 & -12.1491 & 1.0263 & 0.0998 \\
\hline 0.50 & -0.3944 & -1.2889 & 0.1451 & 0.0915 \\
\hline 1.00 & -0.1325 & -0.7649 & 0.1026 & 0.0840 \\
\hline 2.00 & 0.0528 & -0.3944 & 0.0726 & 0.0715 \\
\hline 4.00 & 0.1838 & -0.1325 & 0.0513 & 0.0543 \\
\hline 5.00 & 0.2172 & -0.0657 & 0.0459 & 0.0482 \\
\hline 6.00 & 0.2418 & -0.0164 & 0.0419 & 0.0433 \\
\hline 7.00 & 0.2610 & 0.0219 & 0.0388 & 0.0392 \\
\hline 10.00 & 0.3000 & 0.1000 & 0.0325 & 0.0305 \\
\hline 11.00 & 0.3093 & 0.1186 & 0.0309 & 0.0284 \\
\hline 12.00 & 0.3174 & 0.1349 & 0.0296 & 0.0266 \\
\hline 13.00 & 0.3246 & 0.1492 & 0.0285 & 0.0249 \\
\hline 14.00 & 0.3310 & 0.1620 & 0.0274 & 0.0235 \\
\hline 15.00 & 0.3367 & 0.1734 & 0.0265 & 0.0222 \\
\hline 16.00 & 0.3419 & 0.1838 & 0.0257 & 0.0210 \\
\hline
\end{tabular}

Table 6. Values of $a_{2}, a_{3}, a_{5}$ and $a_{8}$ for $m_{d b}=0.9$.

\begin{tabular}{|c|c|c|c|c|}
\hline$q \mathbf{L}^{2} / \mathbf{M}_{p}$ & $\mathbf{a}_{2} / \mathbf{L}$ & $\mathbf{a}_{3} / \mathbf{L}$ & $a_{5} / L$ & $\mathbf{a}_{8} / \mathbf{L}$ \\
\hline 0.01 & -7.0107 & -11.4829 & 0.5064 & 0.0499 \\
\hline 0.50 & -0.5622 & -1.1946 & 0.0716 & 0.0451 \\
\hline 1.00 & -0.2511 & -0.6983 & 0.0506 & 0.0410 \\
\hline 2.00 & -0.0311 & -0.3473 & 0.0358 & 0.0345 \\
\hline 4.00 & 0.1245 & -0.0991 & 0.0253 & 0.0260 \\
\hline 5.00 & 0.1641 & -0.0359 & 0.0226 & 0.0231 \\
\hline 6.00 & 0.1934 & 0.0108 & 0.0207 & 0.0208 \\
\hline 6.24 & 0.1993 & 0.0203 & 0.0203 & 0.0203 \\
\hline 10.00 & 0.2625 & 0.1211 & 0.0160 & 0.0147 \\
\hline 11.00 & 0.2736 & 0.1387 & 0.0153 & 0.0137 \\
\hline 12.00 & 0.2832 & 0.1541 & 0.0146 & 0.0129 \\
\hline 13.00 & 0.2917 & 0.1677 & 0.0140 & 0.0121 \\
\hline 14.00 & 0.2993 & 0.1798 & 0.0135 & 0.0114 \\
\hline 15.00 & 0.3061 & 0.1906 & 0.0131 & 0.0108 \\
\hline 16.00 & 0.3122 & 0.2004 & 0.0127 & 0.0102 \\
\hline
\end{tabular}




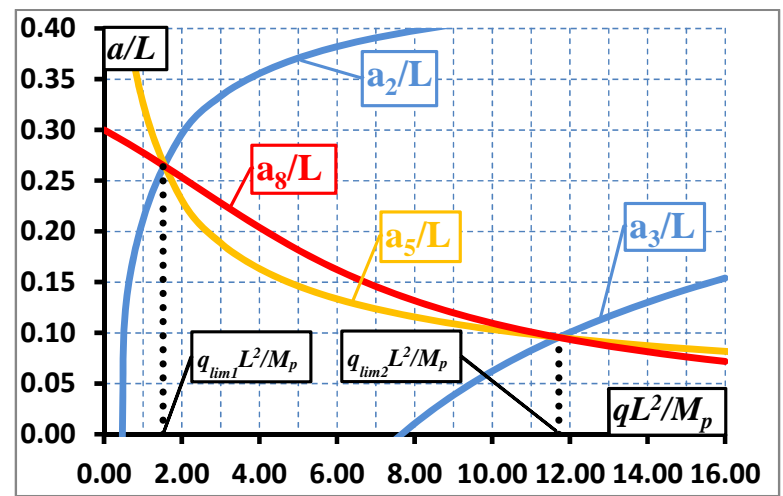

Fig. (4). Limit values $a_{2} / L, a_{3} / L, a_{5} / L$ and $a_{8} / L$ for $m_{d b}=0.4$.

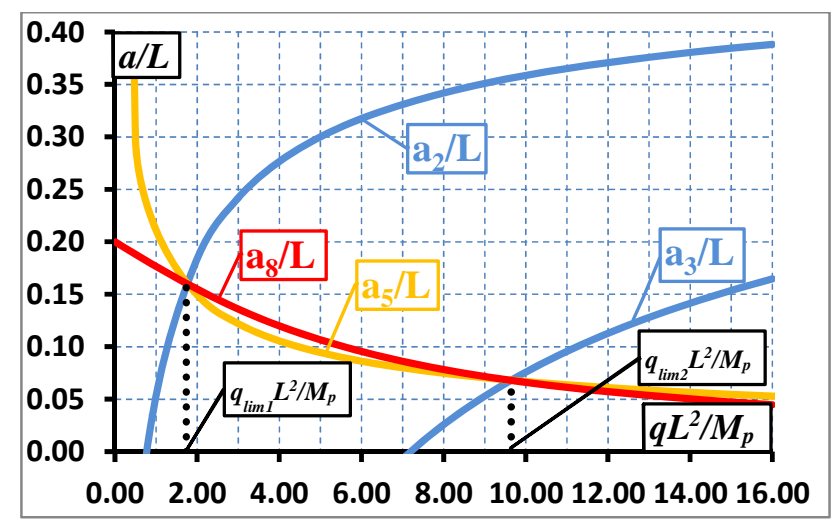

Fig. (6). Limit values $a_{2} / L, a_{3} / L, a_{5} / L$ and $a_{8} / L$ for $m_{d b}=0.6$.

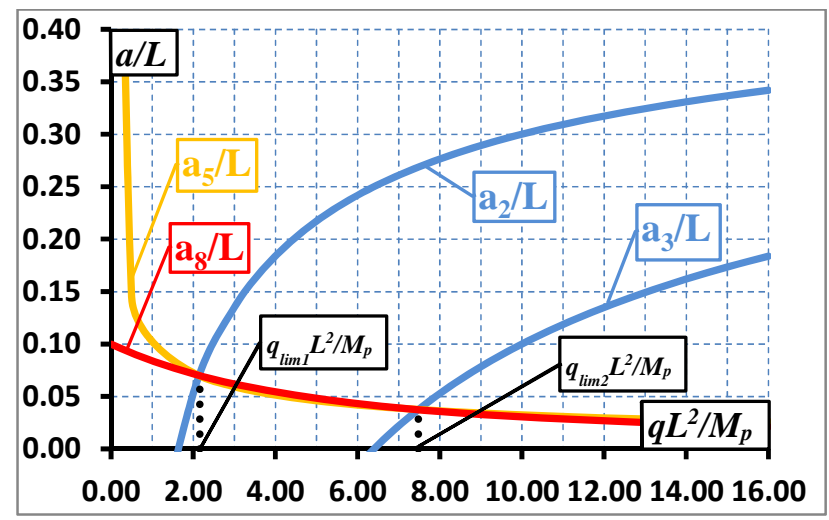

Fig. (8). Limit values $a_{2} / L, a_{3} / L, a_{5} / L$ and $a_{8} / L$ for $m_{d b}=0.8$.

consists in the protection of the beam-to-column connections, i.e. yielding of both "dog-bones" or yielding of one "dog-bone" and of a beam cross section. With the aim of obtaining this design objective it is sufficient to consider only the limit value of $a / L$ provided by the minimum between $a_{5} / L$ and $a_{8} / L$.

This value can be obtained varying $m_{d b}$ for a fixed vertical load $q$ and beam plastic moment $M_{p}$. In other words, for a given $q L^{2} / M_{p}$ the curve representing the upper limit of $a / L$ as a function of $m_{d b}$ can be obtained as depicted in Fig. (10). This figure is, substantially, a design abacus for "dog-bone" location.

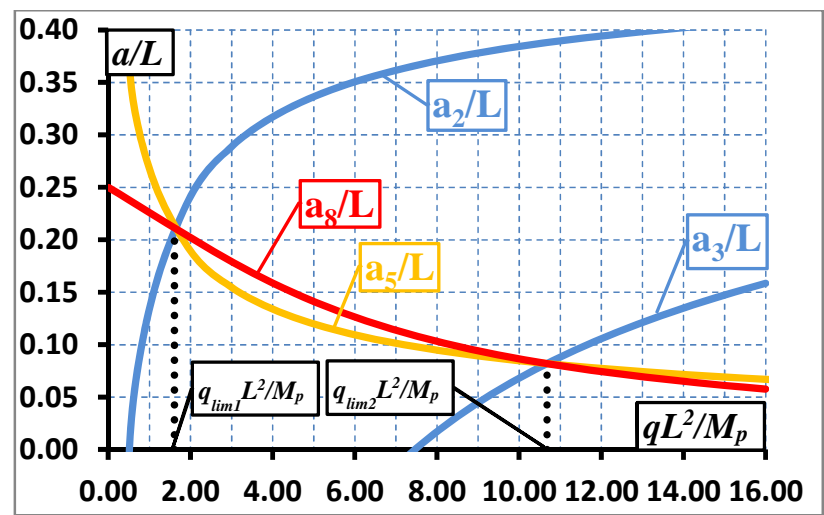

Fig. (5). Limit values $a_{2} / L, a_{3} / L, a_{5} / L$ and $a_{8} / L$ for $m_{d b}=0.5$.

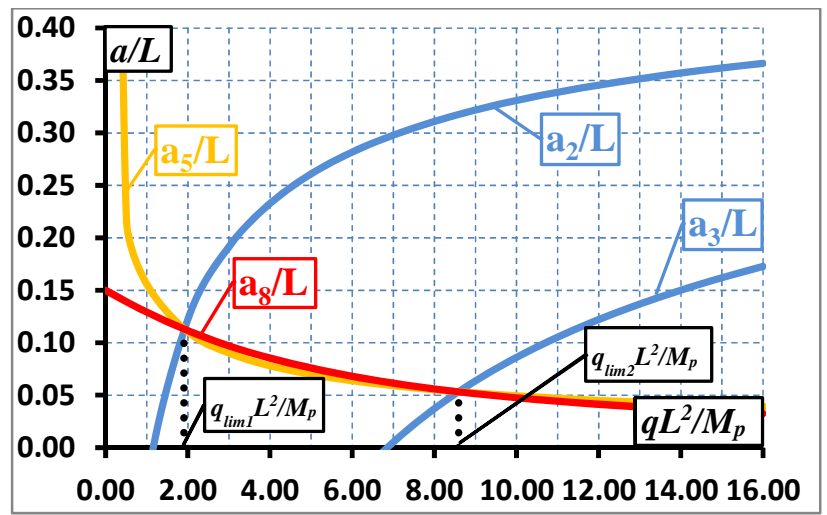

Fig. (7). Limit values $a_{2} / L, a_{3} / L, a_{5} / L$ and $a_{8} / L$ for $m_{d b}=0.7$.

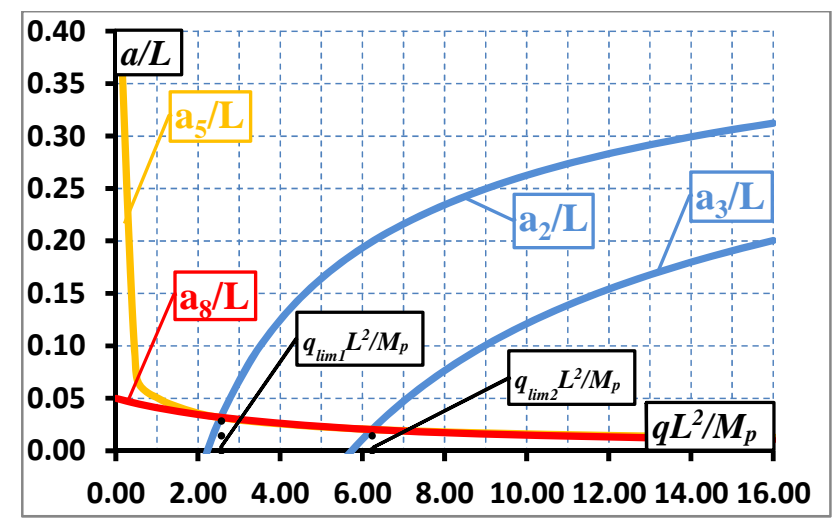

Fig. (9). Limit values $a_{2} / L, a_{3} / L, a_{5} / L$ and $a_{8} / L$ for $m_{d b}=0.9$.

In fact, it includes all the design variables expressed in non-dimensional form. The abacus can be useful also to understand the role played by several parameters. The numerical values used to build Fig. (10) are reported in Tables 7-9. In particular, it is important to underline that, for a given value of $q L^{2} / M_{p}$, an increase of $m_{d b}$ causes the decrease of the admissible value of $a / L$ and, in the case $m_{d b}=1$, an $a / L$ value equal to zero is provided independently of $q L^{2} / M_{p}$. In addition, increasing the vertical load, the admissible $a / L$ value decreases. 


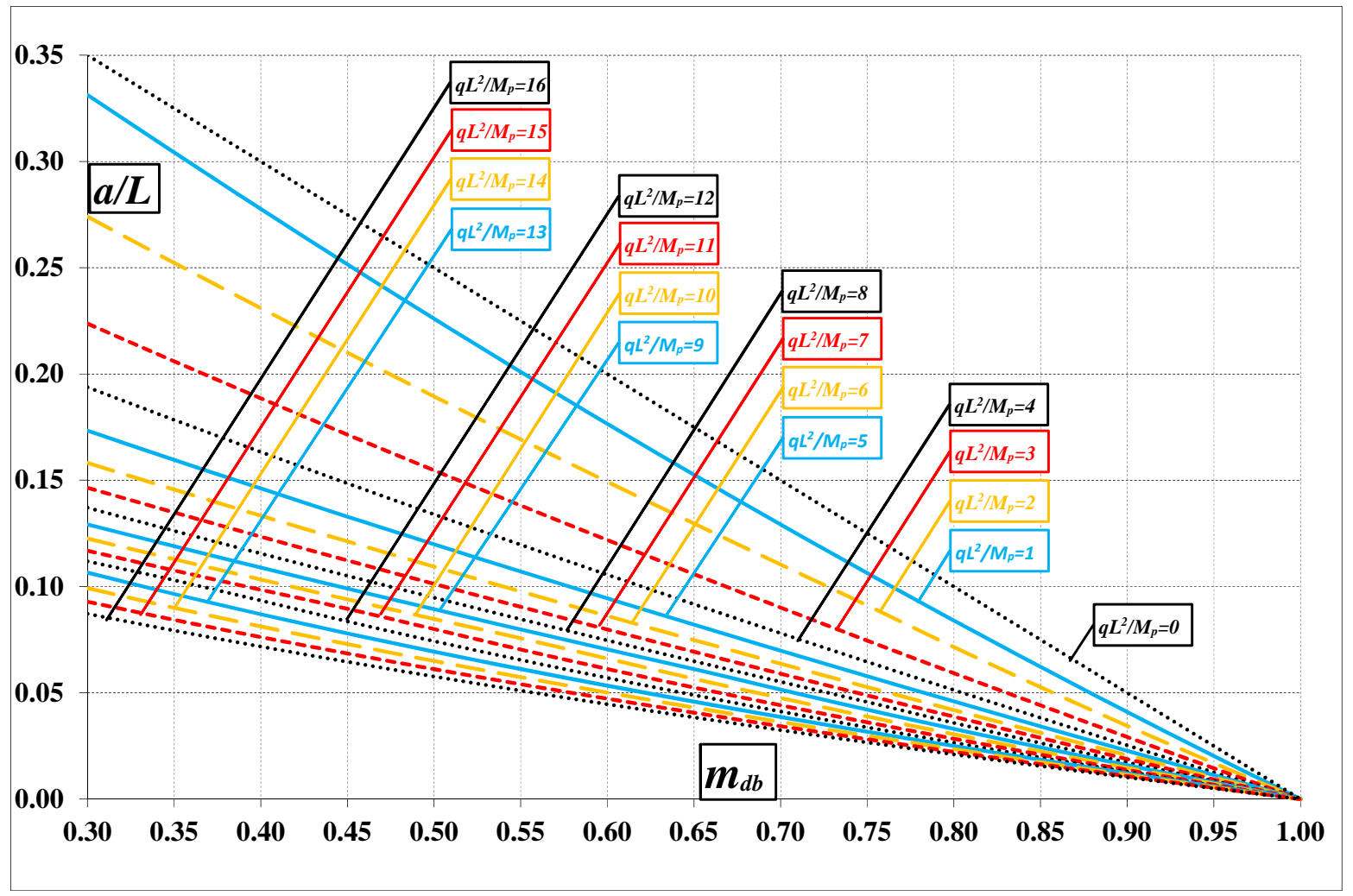

Fig. (10). Design abacus for "dog-bone" location.

Table 7. Limit values of $a / L$ for "dog-bone" location.

\begin{tabular}{|c|c|c|c|c|c|c|}
\hline $\mathbf{m}_{\mathrm{db}}$ & $\frac{q L^{2}}{M_{p}}=0$ & $\frac{q L^{2}}{M_{p}}=1$ & $\frac{q L^{2}}{M_{p}}=2$ & $\frac{q L^{2}}{M_{p}}=3$ & $\frac{q L^{2}}{M_{p}}=4$ & $\frac{q L^{2}}{M_{p}}=5$ \\
\hline 0.30 & 0.350 & 0.331 & 0.274 & 0.224 & 0.194 & 0.173 \\
\hline 0.35 & 0.325 & 0.304 & 0.252 & 0.206 & 0.178 & 0.160 \\
\hline 0.40 & 0.300 & 0.278 & 0.231 & 0.189 & 0.163 & 0.146 \\
\hline 0.50 & 0.250 & 0.226 & 0.189 & 0.155 & 0.134 & 0.120 \\
\hline 0.55 & 0.225 & 0.201 & 0.169 & 0.138 & 0.120 & 0.107 \\
\hline 0.60 & 0.200 & 0.176 & 0.149 & 0.122 & 0.106 & 0.094 \\
\hline 0.65 & 0.175 & 0.153 & 0.130 & 0.106 & 0.092 & 0.082 \\
\hline 0.80 & 0.100 & 0.084 & 0.072 & 0.059 & 0.051 & 0.046 \\
\hline 0.85 & 0.075 & 0.062 & 0.053 & 0.044 & 0.038 & 0.034 \\
\hline 0.90 & 0.050 & 0.041 & 0.034 & 0.029 & 0.025 & 0.023 \\
\hline 0.95 & 0.025 & 0.020 & 0.017 & 0.015 & 0.013 & 0.011 \\
\hline 1.00 & 0.000 & 0.000 & 0.000 & 0.000 & 0.000 & 0.000 \\
\hline
\end{tabular}


Table 8. Limit values of $a / L$ for "dog-bone" location.

\begin{tabular}{|c|c|c|c|c|c|c|}
\hline $\mathbf{m}_{\mathrm{db}}$ & $\frac{q L^{2}}{M_{p}}=6$ & $\frac{q L^{2}}{M_{p}}=7$ & $\frac{q L^{2}}{M_{p}}=8$ & $\frac{q L^{2}}{M_{p}}=9$ & $\frac{q L^{2}}{M_{p}}=10$ & $\frac{q L^{2}}{M_{p}}=11$ \\
\hline 0.35 & 0.146 & 0.135 & 0.126 & 0.119 & 0.113 & 0.108 \\
\hline 0.40 & 0.133 & 0.123 & 0.116 & 0.109 & 0.103 & 0.098 \\
\hline 0.50 & 0.109 & 0.101 & 0.095 & 0.089 & 0.085 & 0.080 \\
\hline 0.55 & 0.098 & 0.090 & 0.085 & 0.080 & 0.076 & 0.070 \\
\hline 0.60 & 0.086 & 0.080 & 0.075 & 0.070 & 0.066 & 0.061 \\
\hline 0.75 & 0.053 & 0.049 & 0.046 & 0.042 & 0.039 & 0.036 \\
\hline 0.80 & 0.042 & 0.039 & 0.036 & 0.033 & 0.031 & 0.028 \\
\hline 0.85 & 0.031 & 0.029 & 0.026 & 0.024 & 0.022 & 0.021 \\
\hline 0.90 & 0.021 & 0.019 & 0.017 & 0.016 & 0.015 & 0.014 \\
\hline 0.95 & 0.010 & 0.009 & 0.008 & 0.008 & 0.007 & 0.007 \\
\hline 1.00 & 0.000 & 0.000 & 0.000 & 0.000 & 0.000 & 0.000 \\
\hline
\end{tabular}

Table 9. Limit values of $a / L$ for "dog-bone" location.

\begin{tabular}{|c|c|c|c|c|c|}
\hline $\mathbf{m}_{\mathrm{db}}$ & $\frac{q L^{2}}{M_{p}}=12$ & $\frac{q L^{2}}{M_{p}}=13$ & $\frac{q L^{2}}{M_{p}}=14$ & $\frac{q L^{2}}{M_{p}}=15$ & $\frac{q L^{2}}{M_{p}}=16$ \\
\hline 0.30 & 0.112 & 0.107 & 0.099 & 0.093 & 0.087 \\
\hline 0.35 & 0.103 & 0.096 & 0.090 & 0.084 & 0.079 \\
\hline 0.40 & 0.093 & 0.087 & 0.081 & 0.076 & 0.072 \\
\hline 0.50 & 0.074 & 0.069 & 0.065 & 0.061 & 0.058 \\
\hline 0.55 & 0.065 & 0.061 & 0.057 & 0.054 & 0.051 \\
\hline 0.60 & 0.057 & 0.053 & 0.050 & 0.047 & 0.045 \\
\hline 0.80 & 0.027 & 0.025 & 0.023 & 0.022 & 0.021 \\
\hline 0.85 & 0.020 & 0.018 & 0.017 & 0.016 & 0.016 \\
\hline 0.90 & 0.013 & 0.012 & 0.011 & 0.011 & 0.010 \\
\hline 0.95 & 0.006 & 0.006 & 0.006 & 0.005 & 0.005 \\
\hline 1.00 & 0.000 & 0.000 & 0.000 & 0.000 & 0.000 \\
\hline
\end{tabular}




\section{CONCLUSION}

The traditional design philosophy of seismic-resistant structures requires that, in case of seismic events having a return period comparable with the average life of the construction, the structure has to remain in elastic range and has to develop limited lateral displacements in order to determine the minimum discomfort to the activities developed in the construction. Conversely, in the case of destructive seismic events, having a return period of about 500 years, the structure has to be able to dissipate the earthquake input energy by means of plastic excursions whose magnitude has to be limited to values compatible with the local and global ductility which the structure is able to supply. In other words, even though the structure is significantly damaged, collapse has to be prevented aiming to assure the safeguard of the human lives. Therefore, seismic-resistant structures have to be designed to obtain two goals; on one hand, they have to possess sufficient strength and stiffness to fulfil the requirements concerning the serviceability limit state and, on the other hand, adequate ductility and energy absorption capacity to fulfil the requirements regarding the ultimate limit state. While the fulfilment of the first goal is easy to be obtained, the latter generally requires more troublesome design procedures which should account for the structural behaviour in plastic range.

In particular, it is universally recognized the need to prevent collapse mechanisms having limited dissipation capacity, such as storey mechanisms, and to promote the development of a collapse mechanism of global type. Moreover, it is always necessary the design of structural details, i.e. connections between dissipative zones and non-dissipative zones, able to guarantee an high local ductility supply. In this paper the criteria for designing "dog-bone" connections have been analysed. In particular, depending on the magnitude of the weakening of the beam section, the "dog-bone" location has to be properly selected in order to protect the beam-tocolumn connections which is one of the goals to be achieved in designing frames adopting such a structural detail.

In addition, the obtained results show that the smallest $m_{d b}$ value provides the widest range where it is possible to locate the "dog-bones"; in fact, increasing $m_{d b}$ the range identified by $a$ reduces up to zero for $m_{d b}=1$.

The provided design abacus for RBS location represents a useful tool to easily understand if the beam-to-column connections are protected or not by the realization of a "dogbone" having a non-dimensional resistance $m_{d b}$, a nondimensional distance from the beam-to-column connection $a / L$ and a non-dimensional value of vertical load $q L^{2} / M_{P}$.

\section{CONFLICT OF INTEREST}

The authors confirm that this article content has no conflict of interest.

\section{ACKNOWLEDGEMENTS}

Declared none.

\section{REFERENCES}

[1] V. Piluso, and G. Rizzano, "Random material variability effects on full-strength end-plate beam-to-column joints", Journal of Constructional Steel Research, vol. 63, pp. 658-66, 2007.
[2] C. Bernuzzi, R. Zandonini, and P. Zanon, "Experimental analysis and modelling of semi-rigid steel joints under cyclic reversal loading", Journal of Constructional Steel Research, vol. 2, pp. 95-123, 1996.

[3] C. Faella, V. Piluso, and G. Rizzano, "A new method to design extended end plate connections and semirigid braced frames", Journal of Constructional Steel Research, vol. 41, pp. 61-91, 1996.

[4] F. Iannone, M. Latour, V. Piluso and G. Rizzano, "Experimental analysis of bolted steel beam-to-column connections: Component Identification", Journal of Earthquake Engineering, vol. 15, pp. 214-44, 2011.

[5] M. Latour, V. Piluso and, G. Rizzano, "Cyclic modeling of bolted beam-to-column connections: component approach", Journal of Earthquake Engineering, vol. 15, pp. 537-63, 2011.

[6] M. Latour, V. Piluso and G. Rizzano, "Experimental behaviour of friction T-stub beam-to-column joints under cyclic loads", Steel Construction, vol. 1, pp. 11-18, 2013.

[7] M. Latour, V. Piluso, and G. Rizzano, "Experimental analysis of innovative dissipative bolted double split tee beam-to-column connections", Steel Construction, vol. 4, pp. 53-64, 2011.

[8] M. Latour and G. Rizzano, "Experimental behavior and mechanical modeling of dissipative t-stub connections", Journal of Structural Engineering, vol. 138, pp. 170-82, 2012.

[9] M. Latour and G. Rizzano, "Innovative Connections for timber panel buildings", International Journal of Earthquake Engineering, 2014 (Epub Ahead).

[10] M. Latour and G. Rizzano, "Cyclic behavior of dissipative xshaped double split tee joints", Journal of Constructional Steel Research, (in Press).

[11] V. Piluso and G. Rizzano, "Experimental Analysis and modelling of bolted T-stubs under cyclic loads", Journal of Constructional Steel Research, vol. 64, pp. 655-69, 2008.

[12] A. Plumier. New idea for safe structures in seismic zones. IABSE Symposium, Mixed structures including new materials, Brussels, 1990.

[13] S. Wilkinson, G. Hurdman, A. Crowther. "A moment resisting connection forearthquake resistant structures", Journal of Constructional Steel Research, vol. 62, pp. 295-302, 2006.

[14] N. Iwankiw, "Seismic design enhancement and the reduced beam section detail for steel moment frames", Practice Periodical on Structural design and Construction, vol. 9, pp. 87-92, 2004.

[15] M.D. Engelhardt, M. Venti, G.T. Fry, S. Jones, and S. Holliday, "Behavior and design of radius cut reduced beam section connections", A draft report of SAC task 7.07a. SAC Joint Venture; 2000.

[16] S.-J. Chen, J.M. Chua, and Z.L. Chou, "Dynamic behaviour of steel frames with beam flanges shaved around connection", Journal of Constructional Steel Research, vol. 42, pp. 49-70, 1997.

[17] N.R. Ivankiw, and C.J. Carter, "Improved ductility in seismic steel moment frames with dogbone connections", Journal of Constructional Steel Research, vol. 46, pp. 1-3, 1998.

[18] N. Iwankiw, and S. Zoruba, "Steel moment frames: resolution of recent seismic detailing and material shape issues", Journal of Constructional Steel Research, vol. 58, pp. 495-510, 2002.

[19] K. Lee, and D.A. Foutch, "Performance evaluation of new steel frame buildings for seismic loads", Earthquake Engineering and Structural Dynamics, vol. 31, pp. 653-70, 2002.

[20] C. Brandon, and U. Chia-Ming, "Cyclic response and design recommendations of reduced beam section moment connections with deep columns", Journal of Structural Engineering, vol. 128, no. 4, pp. 464-473, 2002.

[21] D. Ardeshir, and M. T. Afshin, "Effect of column panel zone characteristics on instability of beams with rbs moment resisting connections", 13th World Conference on Earthquake Engineering Vancouver, B.C., Canada, Paper No. 31, 2004.

[22] M. Ohsakia, H. Tagawab, and P. Panc, "Shape optimization of reduced beam section under cyclic loads", Journal of Constructional Steel Research, vol. 65, pp. 1511-19, 2009.

[23] H. Sang-Whan, M. Ki-Hoon, and S. Bozidar c, "Design equations for moment strength of rbs-b connections", Journal of Constructional Steel Research, vol. 65, pp. 1087-95, 2009.

[24] A.H. Amir, and C. Murude, "Post-Northridge connection with modified beam end configuration to enhance strength and ductility", Journal of Constructional Steel Research, vol. 65, pp.1413-30, 2009.

[25] D.T. Pachoumis, E.G. Galoussis, C.N. Kalfas, and A.D. Christitsas, "Reduced beam section moment connections subjected to cyclic 
loading: Experimental analysis and FEM simulation", Engineering Structures, vol. 31, pp. 216-23, 2009.

[26] K.S. Ajay, and G. Vesmawala, "Study of steel moment connection with and without reduced beam section", Case Studies in Structural Engineering, vol. 1, pp. 26-31, 2014.

[27] C.E. Sofias, C.N. Kalfas, and D.T. Pachoumis, "Experimental and FEM analysis of reduced beam section moment endplate connections under cyclic loading", Engineering Structures, vol. 59, pp. 320-29, 2013.

[28] D.T. Pachoumis, E.G. Galoussis, C.N. Kalfas, and I.Z. Efthimiou, "Cyclic performance of steel moment-resisting connections with reduced beam sections - experimental analysis and finite element model simulation", Engineering Structures, vol. 32, pp. 2683-92, 2010.

[29] W.H. Sang, M. Ki-Hoon, H. Seong-Hoon, and S. Bozidar, "Rotation capacities of reduced beam section with bolted web (RBS-B) connections", Journal of Constructional Steel Research, vol. 70, pp. 256-63, 2012.

[30] CEN 2003. PrEN 1998-1. Eurocode 8: Design of Structures for Earthquake Resistance. Part 1: General Rules, Seismic actions and rules for buildings.

[31] CEN 1993. PrEN 1993-1. Eurocode 3: Design of Steel Structures. Part 1: General rules and rules for buildings.

[32] FEMA 302. NEHRP recommended provisions for seismic regulations for new buildings and other structures, part 1 -provisions. Federal Emergency Management Agency, Washington, DC; 1997.

[33] FEMA 350. Recommended seismic design criteria for new steel moment-frame buildings. Prepared by the SAC Joint Venture for the Federal Emergency Management Agency, Washington, DC; 2000.

[34] F.M. Mazzolani, and V. Piluso, "Plastic design of seismic resistant steel frames", Earthquake Engineering and Structural Dynamics, 26, pp. 167-91, 1997.

[35] A. Longo, R. Montuori, and V. Piluso, "Theory of plastic mechanism Control for MRF-CBF dual system and its validation", Bulletin of Earthquake Engineering (BEEE), pp. 2745-2775, 2014.

[36] M.T. Giugliano, A. Longo, R. Montuori, and V. Piluso, "Failure mode and drift control of MRF-CBF dual systems", The Open Construction and Building Technology Journal, vol. 4, pp. 121-33, 2010.

[37] R. Montuori, V. Piluso, and M. Troisi, "Theory of plastic mechanism control of seismic-resistant MR-frames with set-backs", Open Construction and Building Technology Journal, vol. 6, pp. 404-13, 2012.

[38] A. Longo, R. Montuori, and V. Piluso, "Theory of plastic mechanism control of dissipative truss moment frames", Engineering Structures, vol. 37, pp. 63-75, 2012.

[39] A. Longo, R. Montuori, and V. Piluso, "Failure mode control and seismic response of dissipative truss moment frames", Journal of Structural Engineering, vol. 138, pp.1388-97, 2012.

[40] R. Montuori, V. Piluso, and M. Troisi "Innovative structural details in MR-frames for free from damage structures", Mechanics Research Communications, vol. 58 pp. 146-56, 2014.

[41] R. Montuori, and R. Muscati, "Plastic design of seismic resistant concrete frame", Earthquakes and Structures, (in Press).
[42] R. Montuori, E. Nastri, and V. Piluso, "Advances in theory of plastic mechanism control: closed form solution for Mr-Frames", Earthquake Engineering and Structural Dynamics, (in Press).

[43] R. Montuori, and V. Piluso, Plastic design of steel frames with Dog-Bone beam-to-column joints, Third International Conference on Behaviour of Steel Structures in Seismic Areas, STESSA 2000.

[44] A. Longo, R. Montuori, and V. Piluso, "Failure mode control of Xbraced frames under seismic actions", Journal of Earthquake Engineering, vol. 12, pp. 728-59, 2008

[45] A. Longo, R. Montuori, and V. Piluso, "Plastic design of seismic resistant V-Braced frames", Journal of Earthquake Engineering, vol. 12, pp. 1246-66, 2008.

[46] A. Longo, R. Montuori, and V. Piluso. "Influence of design criteria on the seismic reliability of X-Braced Frames", Journal of Earthquake Engineering, vol. 12, pp. 406-31, 2008.

[47] R. Montuori, E. Nastri, and V. Piluso, "Rigid-plastic analysis and moment-shear interaction for hierarchy criteria of inverted Y EBFrames", Journal of Constructional Steel Research, vol. 95, pp. 7180, 2014.

[48] R. Montuori, E. Nastri, and V. Piluso, "Theory of plastic mechanism control for eccentrically braced frames with inverted Yscheme", Journal of Constructional Steel Research, vol. 92, pp. 122-35, 2014.

[49] M.T. Giugliano, A. Longo, R. Montuori, and V. Piluso, "Plastic design of CB-frames with reduced section solution for bracing members", Journal of Constructional Steel Research, vol. 66, pp. 611-21, 2010.

[50] R. Montuori, E. Nastri, and V. Piluso, "Theory of plastic mechanism control for the seismic design of braced frames equipped with friction dampers", Mechanics Research Communications, vol. 58, pp. 112-23 2014

[51] A. Longo, R. Montuori, and V. Piluso, "Seismic reliability of Vbraced frames: Influence of design methodologies", Earthquake Engineering and Structural Dynamics, vol. 38, pp. 1587-608, 2009.

[52] A. Longo, R. Montuori, and V. Piluso, "Seismic reliability of chevron braced frames with innovative conception of bracing members", Advanced Steel Construction, an International Journal, vol. 5, pp. 367-389, 2009.

[53] R. Montuori, E. Nastri, and V. Piluso, "Rigid-plastic analysis and moment-shear interaction for hierarchy criteria of inverted Y EBFrames", Journal of Constructional Steel Research, vol. 95, pp.7180, 2014.

[54] A. Longo, R. Montuori, E. Nastri, and V. Piluso, "On the use of HSS in seismic-resistant structures", Journal of Constructional Steel Research, vol. 103, pp. 1-12, 2014.

[55] R. Montuori, E. Nastri, and V. Piluso, "Seismic Design of MRFEBF dual systems with vertical links: Ec8 Vs Plastic design", Journal of Earthquake Engineering, (in Press).

[56] R. Montuori, E. Nastri, and V. Piluso, "Seismic Response of EBFrames with Inverted Yscheme: TPMC Versus Eurocode Provisions", Earthquakes and Structures, (in Press).

[57] A. Longo, R. Montuori, and V. Piluso, "Moment Frames - Concentrically braced frames dual systems: Analysis of different design criteria, Structure and Infrastructure Engineering, (in Press).

(C) R. Montuori; Licensee Bentham Open.

This is an open access article licensed under the terms of the Creative Commons Attribution Non-Commercial License (http://creativecommons.org/licenses/by-nc/3.0/) which permits unrestricted, non-commercial use, distribution and reproduction in any medium, provided the work is properly cited. 